\title{
ASEAN Orthopaedic Association Outreach Programmes
}

\author{
YC Lee \\ Kandang Kerbau, Women's and Children's Hospital, Singapore
}

\section{INTRODUCTION}

The ASEAN Orthopaedic Association was founded 32 years ago with the aim of improving relationship amongst orthopaedic surgeons in ASEAN (Association of Southeast Asian Nations), and to elevate the standard of care in the region through education, meetings and research.

With the advent of technology, we thought that travel and communications within ASEAN would improve. However, the reality is that in the 21 st century, advances in computer technology improved virtual interaction, but resulted in less travel and direct interaction amongst the surgeons, making cooperation and integration amongst ASEAN orthopaedic surgeons a challenge for the future.

The number of orthopaedic surgeons in each of the ASEAN countries is growing exponentially. It is imperative that the AOA remains even more relevant today so that the orthopaedic surgeons in the region can cooperate and develop their craft for the benefit of the ASEAN community.

\section{Aims of AOA outreach}

The AOA Outreach Programme was initiated in 2011 to provide a platform for further interaction and cooperation amongst orthopaedic surgeons in ASEAN. The AOA outreach subcommittee organizes groups of volunteers from ASEAN to visit provincial communities, the location to be decided by the host country's national association, to interact with the local surgeons through education and provision of treatment services.

\section{Organisational structure}

Any member country in the AOA can elect to host a programme. The national association must choose the venue, preferably one where infrastructure development and provision of orthopaedic care are deficient and where there exist opportunities for teaching. A local coordinator is then appointed to identify tlocal needs, which are then related to the national association, which in turn informs the AOA outreach subcommittee.

Based on the projected requirements of the host community, the AOA outreach subcommittee then appoints a team leader to solicit volunteers from ASEAN with the necessary expertise to achieve the goals of the particular programme. These volunteers can have various levels of expertise and experiences. The team leader, in communication with the local coordinator, then draws up a programme, and delegates responsibilities to each of the volunteers.rprogramme may include didactic lectures, symposia, clinical case presentations and discussions, workshops, outpatient clinics, patient management and surgeries. Thhoice and combination of these activities depend very much on the needs and requirements of the local host community and the resources available to each volunteer team.

Each volunteer makes their own travel arrangements and must raise their own travel expenses. The AOA outreach subcommittee facilitates processing of visas, coordination between the various national associations, and when possible, provides some funding to ensure that the programme can be held as planned.

\section{Responsibilities of local hosts}

Once volunteers make their way to the host community, the local coordinator is responsible for local transportation, housing and food requirements of the volunteers during the duration of the expedition. The local coordinator must source local funding for these purposes. Pharmaceutical and medical equipment companies are often tapped for local funding needs. Throughout the duration of the expedition, there are ample opportunities for interaction between volunteers and local community doctors. The local coordinator is also responsible for the non-academic activities to facilitate interactions and to showcase the local cultures and customs.

\section{Programmes to date}

\section{Klaten Outreach (Table I)}

The inaugural AOA outreach project was conducted in Klaten, Indonesia from 18-20 March 2011. The provincial Dr Suradji Tritonegoro hospital in Klaten was in the process of acquiring knee arthroscopic instrumentation, and local orthopaedic surgeons had no experience performing arthroscopic or total knee replacement surgeries. Dr Romaniyanto from Klaten was the local programme coordinator and there were 5 volunteers from Singapore and Thailand. The outreach theme of was " Update on Trauma Management". They conducted an outpatient clinic with the resident doctors at a local hospital at which interesting clinical problems were presented and discussed. They also took part in a symposium on arthroscopic knee surgery and trauma management at Soeharso Surakarta together with the 


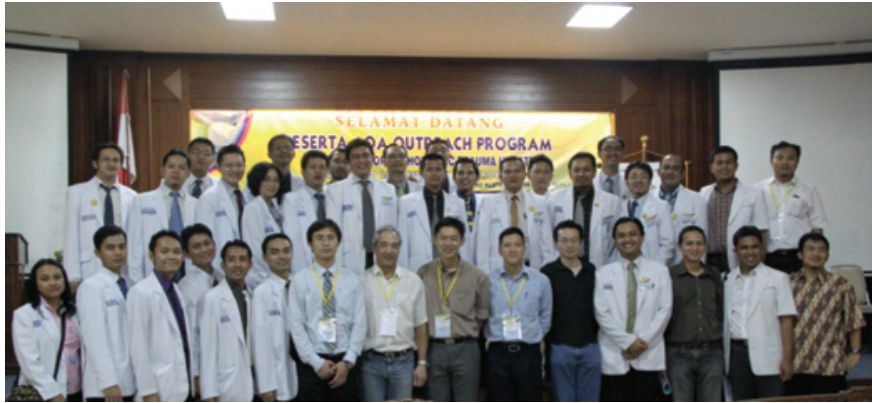

Volunteers with Residents

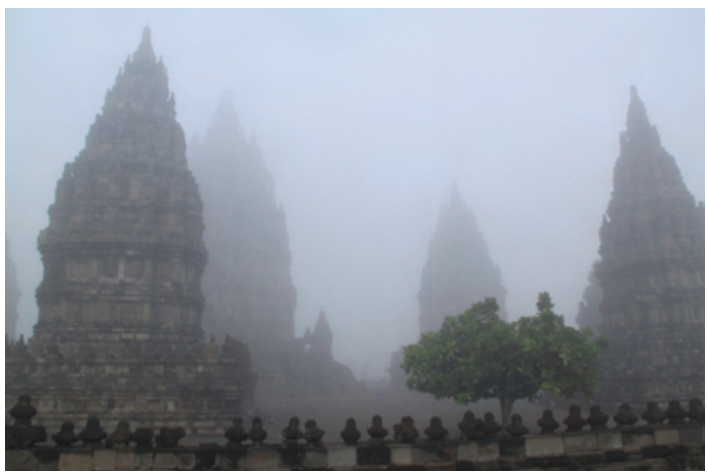

Prambanan Temple

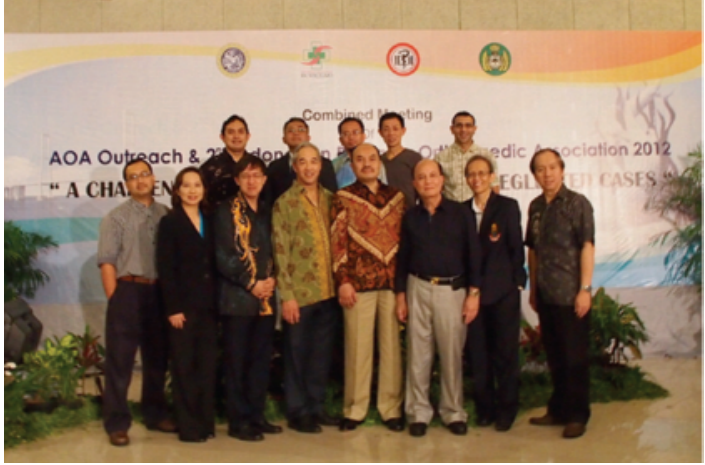

Local \& overseas faculty

local faculty headed by Dr Ismail from Solo. There were more than 80 regional participants for this symposium.

A total knee arthroplasty workshop was performed using saw bones. Eight surgeries were also performed consisting of 3 arthroscopic knee surgeries, 2 operations on malunited tibial fractures, and 3 total knee replacements. These surgeries involved hands-on demonstrations for the local surgeons, and for those unable to be in the operating theatre, there was live video projection to a viewing room. Funding for the arthroplasty implants for total knee replacements came from generous industry donations.

Volunteers were treated to local Sudanese and Javanese cuisine during their stay and enjoyed local hospitality. There was also an opportunity to visit the historical world heritage site at Prambanan, and the active Merapi volcano before departure from Indonesia.

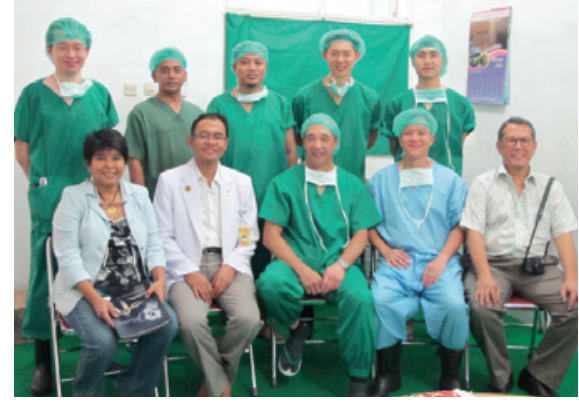

Dr Romaniyanto \& Dr Dohar Tobing

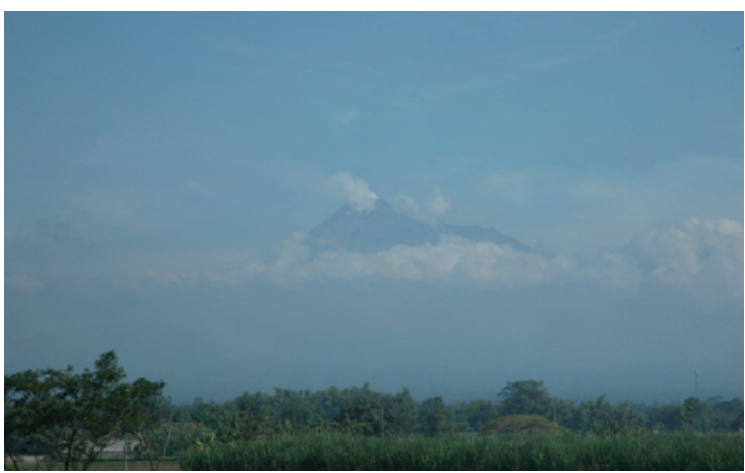

Merapi Volcano

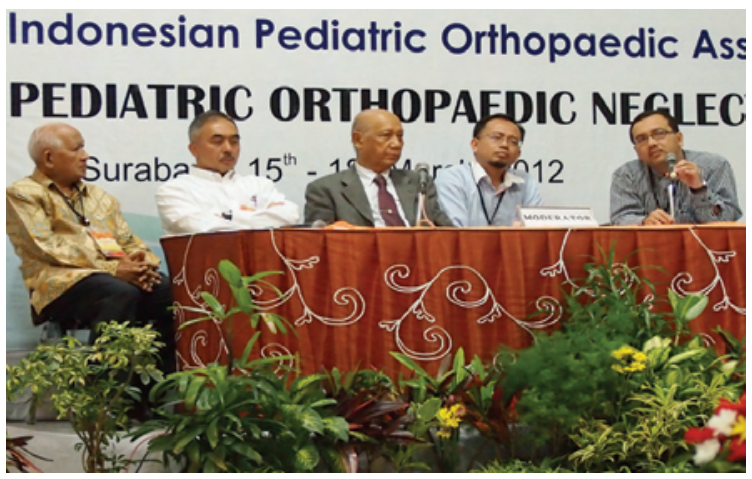

Speakers at 2012 symposium

\section{Surabaya outreach (Table II)}

The second outreach programme was conducted in Surabaya, Indonesia from 16 to 18 March 2012. The theme was "Challenges in Paediatric Orthopaedics - Neglected Cases". Prof Sharaf Ibrahim was the leader of the team of 10 volunteers from Malaysia, Singapore, Philippines and Thailand. Prof Tri Wahyu Martanto was the local coordinator. One hundred ninety participants attended this meeting, many coming from the surrounding districts and provinces.

Ten members from the Indonesian Paediatric Orthopaedic Association, together with the overseas volunteers presented didactic lectures, took part in symposia and clinical case discussions, and resident teaching. A Ponseti demonstration and workshop on clubfoot models was presented; participants in the workshop were then guided with their newly acquired skills to treat infants with varying degrees of 

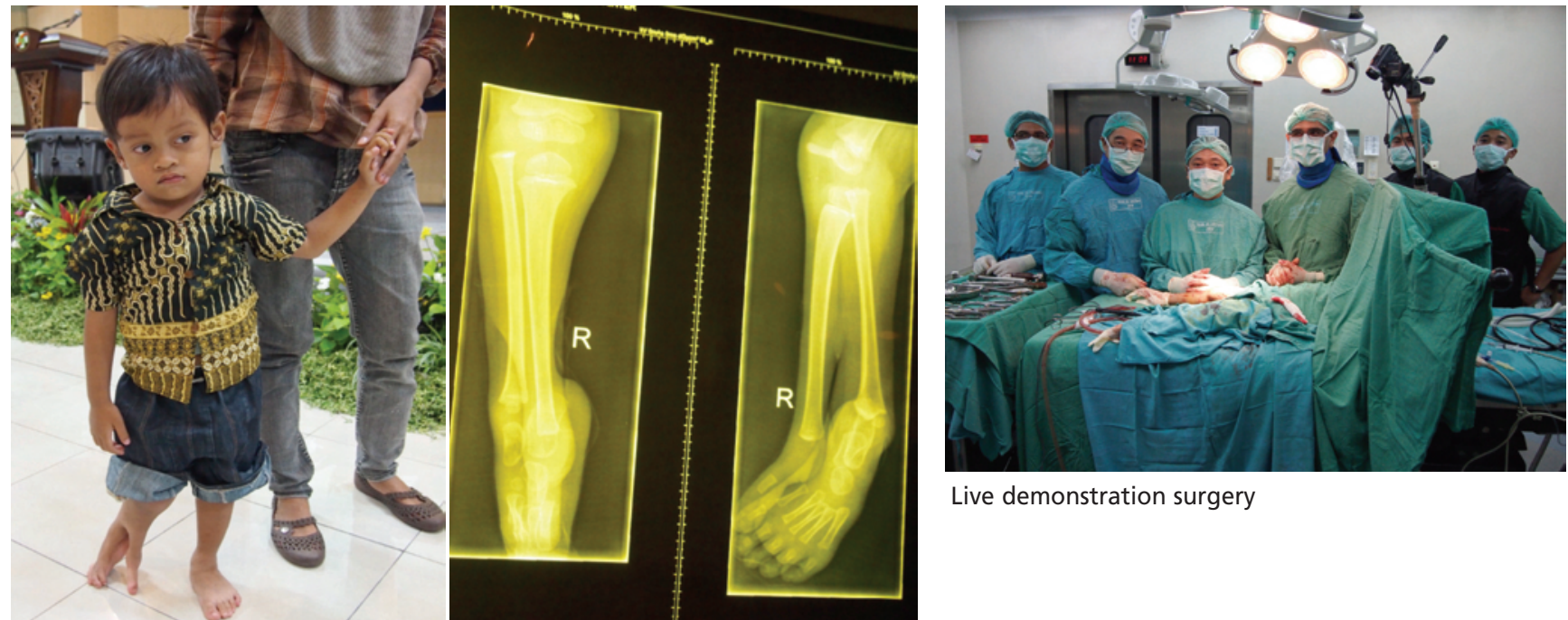

Live demonstration surgery

Unusual and interesting clinical cases
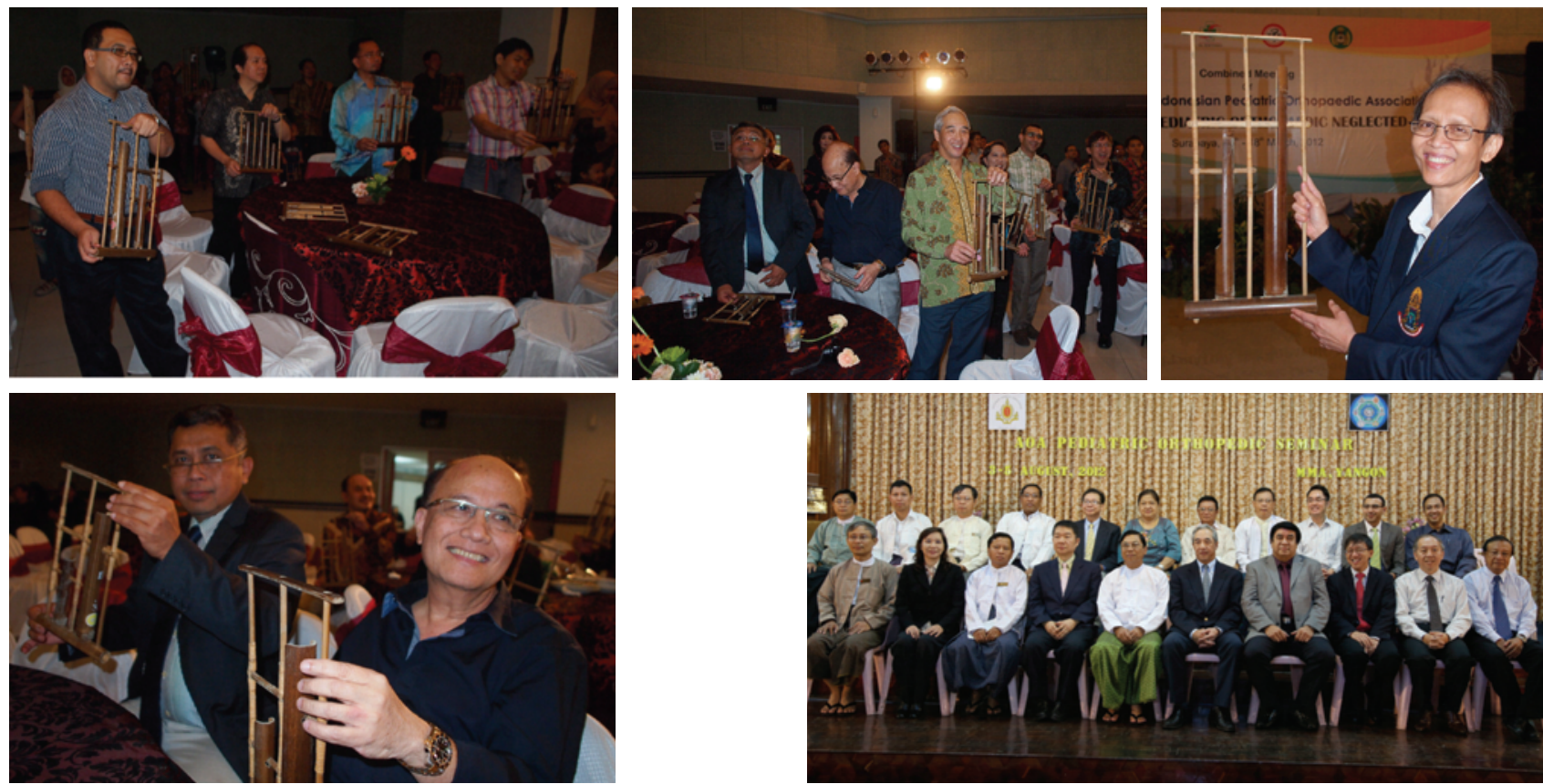

Angklong ensemble

Volunteers with members of Myanmar Medical Association

foot deformities. Surgeries were performed on a severely deformed foot, and on a malunited femoral fracture using intra-medullary elastic nailing. These procedures were also telecast live to programme participants who could not be in the operating room.

There were many opportunities for social interaction amongst the volunteer faculty and the regional participants. The visitors were introduced to local cultural dances, and learned to play the angklong. The more adventurous were also treated to a ride on inflatable boats on the rapids that traverse the nearby mountainous terrain.

\section{Yangon outreach (Table III)}

From 3 to 5 August 2012, another team participated in our third outreach programme in Yangon, Myanmar. Prof Kamolporn Kaewpronsawan led a team of 10 volunteers from Malaysia, Singapore, Philippines and Thailand. The local coordinator was Prof Myint Thaung, President of the Mynamar Medical Association. The outreach theme was "Paediatric Orthopaedics". There were 70 participants in this meeting.

\section{Ponseti workshop and demonstration}

As in our other programmes, the volunteers presented didactic lectures, conducted clinical case discussions and 


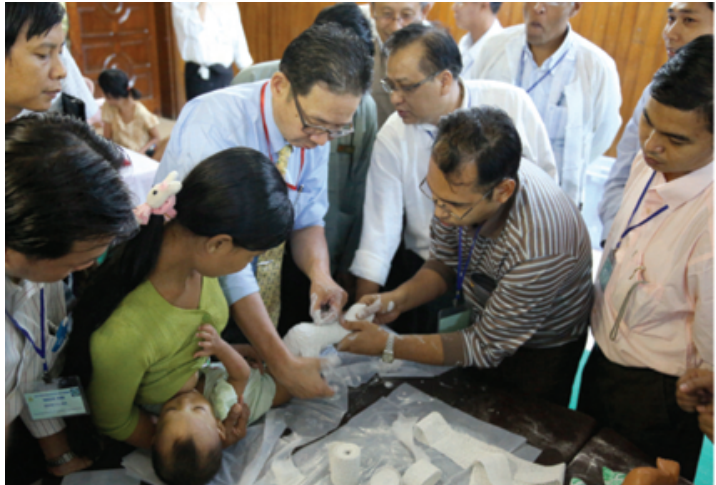

Ponseti workshop and demonstration

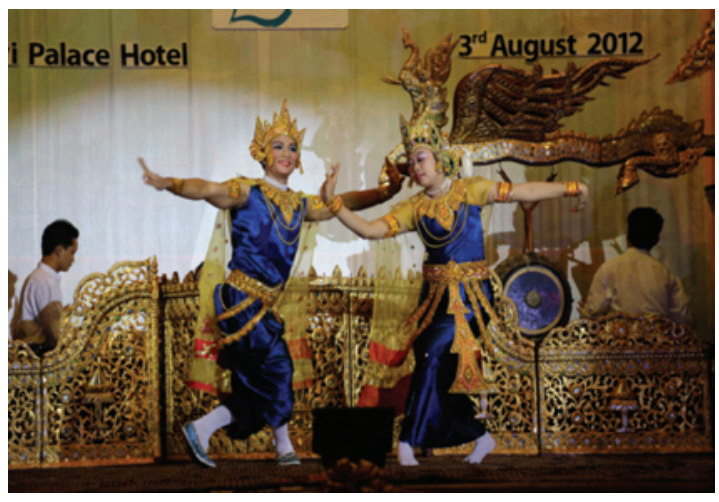

Cultural enrichment
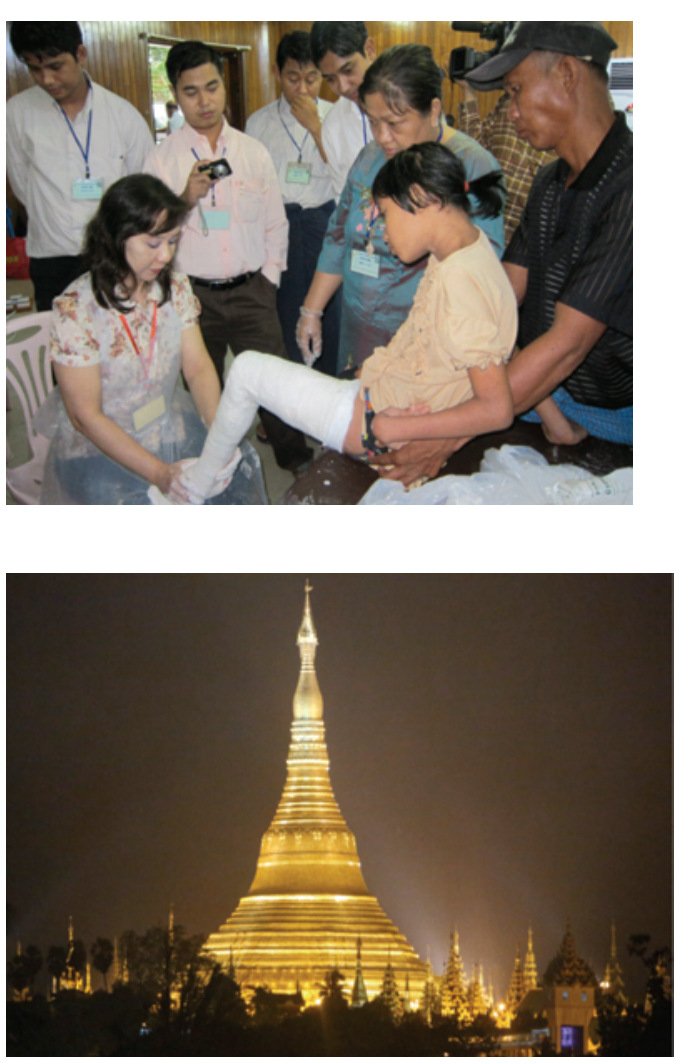

Shwedagon Pagoda symposia. A Ponseti workshop was presented using clubfoot models, and the volunteers demonstrated the Ponseti technique on patients with foot deformities.

Volunteers had the privilege of visiting some of the more famous attractions such as ornate and beautiful pagodas during their short stay. The local hosts also organized a cultural evening to showcase their rich heritage for the benefit of the volunteers.

\section{Future projects}

With each completed project, more members of the ASEAN community were introduced to the unique camaraderie that characterizes the AOA spirit. Like a stone rolling down a slope, momentum is slowly gaining. More volunteers are now aware of these projects, and national associations also realize the benefits it brings to the communities.

The next outreach programme will be in Mandalay, Myanmar from 22 to 24 February 2013 with a theme of " Paediatric Trauma and Infections ". Others being planned for the future include:

- Manado, Indonesia in March 2013

- Mindanao, Philippines in April 2013

- Kuching, Sarawak in May 2013

We plan to involve non-faculty personnel in our outreach programmes, and invite them to attend academic programmes, interact with the local fraternity and share their knowledge and experiences. However, these participants will have to make their own travel arrangements, and for their own accommodation and meals.

\section{How to get involved?}

The aim of the AOA outreach programmes is to involve many ASEAN surgeons as volunteers and to reach out to as many communities as possible. However, marrying the needs of each community with the expertise of the volunteers is a challenge. Each national association should design plans for future projects in their own country, choose project locations, and decide on local requirements and the timing of the projects. The AOA outreach subcommittee can then collate these requests and organize teams of volunteers as resources allow.

Ideally, each country's national association or the AOA will have a registry of volunteers that includes, email and other contact info, special interests, skills, and experience for each country. Whenever a special project is planned, the AOA subcommittee can then email these potential volunteers for their participation.

\section{Extension of the program}

Programmes to date involved qualified surgeons as volunteers, with the intention of benefitting and providing education of community doctors. In the future, we can 
Table I: Klaten Outreach Volunteers and Faculty

\begin{tabular}{|ll|}
\hline Volunteers & Local Faculty \\
\hline Dr. Peter Lee, Team Leader & Prof. Dr. Respati S. Drajat \\
Dr. Lim Jit Kheng & Dr. Pamudji Utomo \\
Dr. Puah Ken Lee & Dr. Ismail Mariyanto \\
Dr. Suwicha Sripadungkul & \\
\hline
\end{tabular}

consider involvement of ancillary medical staff, students and even the lay public in the educational programmes.

Infrastructure improvement and development can be a future objective but this would require higher funding levels. Raising and transferring funds across borders is an administrative challenge and will have to be studied closely before implementation.

\section{CONCLUSION}

The challenge for any organization is to remain relevant to the needs of its members. As the membership increases in size, and with rapid subspecialty development creating
Table II: Surabaya Outreach

\begin{tabular}{|ll|}
\hline Volunteers & Local Faculty \\
\hline Prof. Sharaf Ibrahim, & \\
Team Leader & Prof. IP Sukarna \\
Prof. Saw Aik & Prof. Ketut Siki Kawiyana \\
Prof. Abdul Razak & Prof. Chairuddin Rasjad \\
Prof. Abdul Halim Rasyid & Prof. Hafas Hanafiah \\
Prof. James Hui & Dr. Paruhum Ulitua Siregar \\
Dr. Peter Lee & Dr. Komang Agung Irianto \\
Dr. Arjandas Mahadev & Dr. Tri Wahyu Martanto \\
Mr. Gary Yeo & Dr. Yoyos Dias Ismiarto \\
Dr. Julyn Aguilar & Dr. Ismail Mariyanto \\
Dr. Kanyika Chamniprasas & Dr. Aryadi Kurniawan \\
& \\
\hline
\end{tabular}

splinter groups that form smaller organisations, the AOA must constantly reinvent itself to continue to serve the needs of its members. Outreach programmes allow existing members to get together for a common and worthwhile cause, and also create a platform for special interest groups to promote their development and cooperation. It is indeed a very good vehicle for the AOA to continue its growth and remain relevant for the years ahead ! 